\title{
Mapping Mars at Global to Human Scales
}

Brent A. Archinal, Randolph L. Kirk, Elpitha Howington-Kraus, Mark R. Rosiek, Laurence A. Soderblom, Ella M. Lee

U. S. Geological Survey, Astrogeology Team, 2255 N. Gemini Drive, Flagstaff, AZ 86004, USA (barchinal@usgs.gov)

We report on current Mars mapping projects in support of NASA planetary exploration. This includes a summary of the current state and accuracy of such mapping at global, regional, and local (human) scales. The availability of Mars Orbiter Laser Altimeter data has revolutionized such mapping. Aside from its use as a global topographic dataset, images can easily be correlated to it with absolute uncertainties of $\approx 100 \mathrm{~m}$ horizontally. We are using this to create a revised version of the global Mars digital image mosaic (MDIM) that will have absolute errors of $\approx 231 \mathrm{~m}$ (one pixel) and improved cosmetic characteristics. We are undertaking stereo-topographic mapping at regional to local scales, using Viking and Mars Orbiter Camera Narrow Angle (NA) images, with horizontal resolutions of 600 to $5 \mathrm{~m}$, and expected vertical precision of 200 to $1 \mathrm{~m}$. Derived topography and altimetric information can also be used to calibrate shape-from-shading (photoclinometry) topographic models at down to single-pixel resolution (i.e. $1.4 \mathrm{~m}$ for NA images). Products of these efforts have a multitude of purposes, from assisting in large-scale geologic mapping, to characterizing the geology/safety of proposed landing sites. Plans are underway to also use THEMIS, HRSC, and HiRISE camera data in future efforts. 